\title{
Energy or information? The role of seed availability for reproductive decisions in edible dormice
}

\author{
Karin Lebl · Klaus Kürbisch • Claudia Bieber • \\ Thomas Ruf
}

Received: 1 April 2009 / Revised: 10 November 2009 / Accepted: 14 November 2009 / Published online: 27 November 2009

(C) The Author(s) 2009. This article is published with open access at Springerlink.com

\begin{abstract}
The edible dormouse is a specialized seed predator which is highly adapted to the fluctuations of food availability caused by mast seeding of beech and oak trees. Dormice produce young just in time with maximum food availability, and can completely skip reproduction in years with a lack of seeding. Because their decision to reproduce or not in any particular year is made long before the ripe seeds are available, it seems that dormice can anticipate the upcoming mast situation. We tested the hypothesis that the presence of high caloric food in spring affects their reproductive decision. Therefore, we supplementary fed dormice in a field experiment from spring to early summer with sunflower seeds, which also contain a high amount of energy. Supplemental feeding caused significant increases in the proportion of reproducing females and reproductively active males. These results suggest that edible dormice may use the occurrence of an energy rich food resource to predict the autumnal mast situation. Further, our data indicate that the decision to reproduce was not the result of an increased body mass due to the consumption of surplus food, but that sufficient seed abundance acts as an environmental signal to which dormice adjust their reproduction.
\end{abstract}

Keywords Environmental signals - Food availability · Glis glis · Mast seeding · Reproduction .

Supplemental feeding

Communicated by G. Heldmaier.

K. Lebl $(\bowtie) \cdot$ K. Kürbisch · C. Bieber · T. Ruf

Research Institute of Wildlife Ecology,

University of Veterinary Medicine Vienna,

Savoyenstrasse 1, 1160 Vienna, Austria

e-mail: Karin.Lebl@vetmeduni.ac.at

\section{Introduction}

The exact timing of producing offspring is an important factor for an animal's lifetime reproductive success. In the seasonal environment of temperate zones the optimal time occurs typically at times of high food availability to support the energetically demanding lactation and to allow a fast post-weaning growth of the young (see Goldman 1999). In many cases the period of maximal food availability follows a regular annual rhythm and therefore many animals use photoperiodic cueing or an endogenous circannual clock to anticipate and prepare for the ample times (Bronson 1988). However, not all food resources are that easy to predict. Various terrestrial ecosystems are characterized by "pulsed resources", i.e., occasional, short periods of resource superabundance followed by a decrease over time (Ostfeld and Keesing 2000; Yang et al. 2008). In European deciduous forests the mast fruiting of large trees like beech (Fagus sylvatica) and oak (Quercus spec.) represent such resource pulses occurring at irregular intervals, which alternate with years of intermediate or completely absent seed production (Hilton and Packham 2003; König and Knops 2000).

The edible dormouse (Glis glis), a small, arboreal hibernator, shows several remarkable adaptations to fluctuations in mast seeding, and life-history characteristics related to pulsed resource exploitation. Whereas adult dormice can live (and store enough fat for hibernation) on alternative food items like fruits, leaves, and other seeds (Fietz et al. 2005), a high availability of energy-rich tree seeds in autumn is essential for juvenile dormice to survive their first winter. Dormice litter only once per year in July/ August, which is extremely late in the active season, compared to other hibernators (Bieber and Ruf 2004). This production of pups just in time with the availability of ripe, high-caloric seeds on tree branches apparently optimizes 
survival and pre-hibernation fattening of their young (Pilastro et al. 2003; Schlund et al. 2002). The disadvantage of this highly specialized adaptation is that in years without beechnuts or acorns the survival of juveniles would be very low. It is therefore not surprising to find a strong correlation between the mast of beech or oak and the reproduction of dormice in European deciduous forests where nearly all edible dormice reproduce in full mast years, only parts of the population reproduce in intermediate mast years, and whole populations skip reproduction in years without seed production (Bieber 1998; Bieber and Ruf 2004; Pilastro et al. 2003; Schlund et al. 2002).

Because young are born before the first beech seeds are ripe, the decision to reproduce has to be made much earlier in the season, when the future masting situation appears to be still uncertain. In years with a complete lack of seeding, males remain in a state of reproductive quiescence, while in years with seed production they start to develop testes shortly after their emergence from hibernation (Bieber 1998; Fietz et al. 2005; Schlund et al. 2002). In females gonadal states have not been assessed, but it is likely that they also remain sexually quiescent in years of reproduction skipping. Anticipation of future food pulses was also found in tree squirrels which produce a second, additional litter prior to mast seeding (Boutin et al. 2006). For both dormice and squirrels, it is still unclear which environmental cues convey the signal that controls reproduction. A possible cue for the upcoming masting situation could be secondary plant components of beech and oak trees (Bieber 1998). Plant components, like phytoestrogens or 6-MBOA, have been shown to affect reproduction in many mammals (e.g., Butterstein and Schadler 1988; Malaivijitnond et al. 2004). It has also been hypothesized that the presence of reproductive structures of trees, such as seed buds may be likely candidates for the decisive cue (Bieber 1998; Fietz et al. 2005; Ruf et al. 2006). Even unripe beechnuts (i.e., buds) in July already have a high fat content of $>15 \%$ (Bieber and Ruf 2004), and their presence or absence may affect reproductive decisions. To test the hypothesis that reproduction in dormice is triggered by the presence of high caloric food early in the active season, we carried out a supplemental feeding experiment in a free-living population. Because it is not feasible to either collect or remove large amounts of unripe beechnuts or acorn, we provided energyrich sunflower seeds for part of the population in spring and early summer up to the birth of young, but not during the most energy demanding phase of peak lactation (which takes place mid to end August). We envisioned several possible outcomes of this experiment. If supplemental feeding of seeds does not affect reproduction, then the reproductive decision might be triggered by other cues, e.g., secondary plant components. If reproduction is indeed enhanced by supplemental feeding, the additional food may act in two different ways: Females may gain fat reserves to be used during later lactation. In this case, body weight around the time of mating (as a proxy for fat reserves) should be a crucial factor for the reproductive decision. Alternatively, females may consume supplemental food instead of natural forage, but do not use it to build up fat deposits. In this case, reproductive decisions may be independent of body mass and edible dormice would use the presence of high caloric food as an environmental signal only.

\section{Material and methods}

\section{Study area and data collection}

The study was conducted in the Vienna Forest, near St Corona, Austria $\left(48^{\circ} 05^{\prime} \mathrm{N}, 15^{\circ} 54^{\prime} \mathrm{E}\right.$; altitude $500-850 \mathrm{~m}$ asl). It includes approximately 1,860 ha deciduous forest dominated by beech (Fagus sylvatica, 65\%), the remaining species being mostly spruce (Picea abies, 14\%), larch (Larix decidua, 8\%) and fir (Abies alba, 5\%). Forest inventory data were provided by the federal Austrian forest-agency. At a height of 2-3 m, 184 nest boxes have been installed in 1984, and since then the total number of dormice inhabiting the boxes has been recorded once per year in fall (Bieber and Ruf 2004). Nest box distribution is irregular (along trails) and not ordered in a grid-pattern (mean distance to the nearest neighbor nestbox $123.1 \pm 7.1 \mathrm{~m}$ ). Approximately $70 \%$ of these nest boxes are occupied by dormice each year, which use them during the active season to rest during daytime and to rear their young. Between April and October 2007, the nest boxes were checked for the presence of dormice every other week. Newly captured animals were marked individually with subcutaneously injected transponders (BackHome BioTec ${ }^{\circledR}, 13.8 \mathrm{~mm} \times$ $2.1 \mathrm{~mm}$ ). They were weighed (to the nearest $1 \mathrm{~g}$ ), tibia length was measured (with caliper to the nearest $0.5 \mathrm{~mm}$ ), and sex, age-class and reproductive state were recorded at each capture. Dormice can be reliably classified as juveniles (before first hibernation), yearlings (after first hibernation) and adults (after their second hibernation) from their size, tibia length and fur color (Bieber 1998; Schlund 1997; Vietinghoff-Riesch 1960). Yearlings are already sexually mature (Bieber 1998). Reproductive state in males was assessed from the size of testes measured with calipers to the nearest $0.5 \mathrm{~mm}$. Testes volume was calculated from the length and width of the left testis using the formula of a spheroid. It was also recorded if the testes remained in the regressed state (like during hibernation) and hence were not tangible. Females were classified as reproductive if they were found in the same nest box with juveniles (not older than 4 weeks) and/or if they were captured with visible, enlarged mammae. If a female was captured at least twice 
within the time of young-rearing (week 31-39 of the year; Fig. 1) without young and/or visible mammae, it was classified as non-reproductive. This conservative assignment to a reproductive state caused a considerable reduction of the sample size, but minimizes possible errors due to misclassification. All captured dormice were returned to their nest box immediately after the measurements. To avoid major disturbances of mothers with small young $(<15$ days), which could lead to infanticide or abandoning (König 1960), we only recorded the mother's ID and litter size and did not carry out any measurements in these cases.

\section{Supplemental feeding}

Since edible dormice sometimes use several nestboxes within their home range, we could not randomly choose nestboxes from the entire area for the supplemental feeding experiment. Therefore we selected an area of approximately $30 \%$ of the whole study site for the supplemental feeding, which included 59 nest boxes. In 2006, the year prior to the supplementary feeding experiment, those areas did not differ in the percentage of reproductively active females $(85.3 \%$ in the control area, and $81.5 \%$ in the supplemental feeding area, $\chi^{2}=0.159, d f=1, P=0.690$, $N=61$ ). The supplemental feeding and control area did not differ with respect to altitude, structure or plant species present. However, the age of the main layer of trees was somewhat lower in the supplemental feeding $(52.9 \pm 4.7)$ area than in the rest of the study site (control area: $69.1 \pm 2.9$ years). Since older trees expectedly may produce more seedbuds a potential bias in the analysis of reproductive decisions caused by this difference would only increase the proportion of reproductively active animals in the control area. Therefore the effect of the supplemental feeding, if any, might be slightly reduced. Animals were assigned to the area in which they were captured. All but three out of 424 dormice $(0.7 \%)$ stayed within their area, indicating that access of control-area animals to supplementary food was extremely unlikely. The three adult males captured in both areas where excluded from the analysis. Nest boxes at the supplemental feeding area were provided with $200 \mathrm{~g}$ sunflower seeds every week from the end of May (week 21; when the first seeds buds on trees are available) to mid July (week 30; Fig. 1). Sunflower seeds were used because at the study site and surrounding woods, branches with unripe beechnuts or acorn start at heights of $10-20 \mathrm{~m}$ only and reach up to $\sim 50 \mathrm{~m}$ which makes it impossible to either collect and redistribute, or remove, significant amounts of natural seeds. We provided the sunflower seeds directly in the nestbox to assure that only dormice and no other animals eat them. Birds (in this area mostly great tits) breed and therefore use the nestboxes mainly in April to May (i.e., mainly before dormice emerge), and avoid nestboxes where dormice have been, because dormice occasionally feed on eggs and nestlings (Adamík and Král 2008). Squirrels are too big and do not fit through the entrance of the nestbox. Dormice readily consumed most seeds, and hulls and unconsumed seeds from the previous week were removed from the nest box before refilling. In the weeks between the capture events (when we just refilled the nest boxes) dormice were removed from their nest box for a very short time only. In the week after the last feeding event all remaining seeds were removed. We choose sunflower seeds because they are, similar to beech seeds, rich in fat and energy content $[24.1 \mathrm{~kJ} / \mathrm{g}$ in beech seeds and $24.5 \mathrm{~kJ} / \mathrm{g}$ in sunflower seeds (USDA 2007)]. The year 2007 was a year of low beech seeding at our study area, a visual inspection showed that approximately $30 \%$ of beech trees were fruiting.

\section{Statistical analysis}

For our analysis we excluded weeks in which we captured only one dormouse (capture weeks 19 and 21) and those in

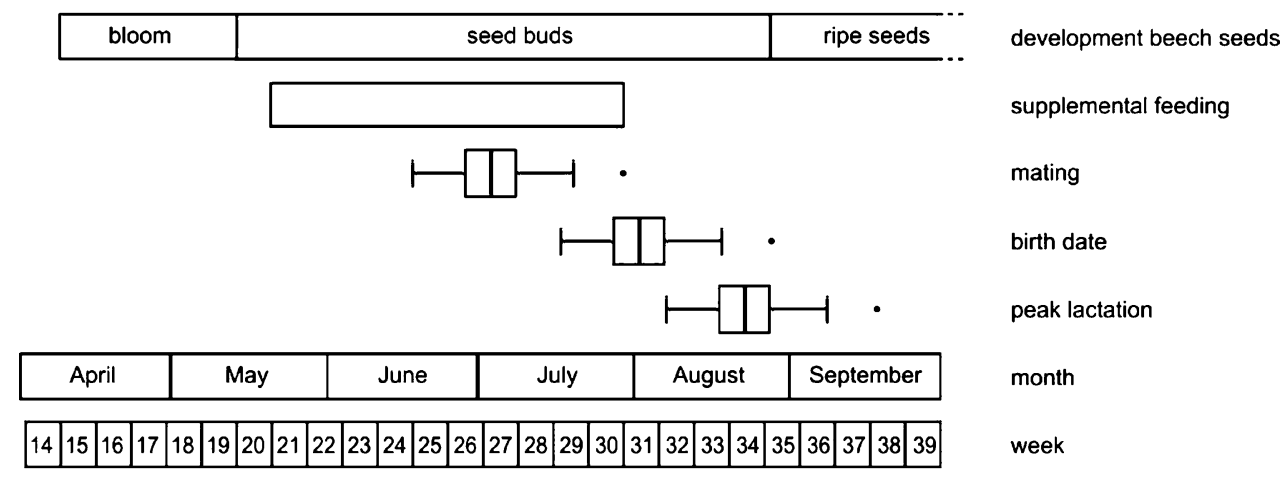

Fig. 1 Time course of the supplemental feeding experiment. Month, week, birth date, estimated mating date (gestation period of approximately 30 days according to König 1960) as well as the time of the peak metabolic rate during lactation (about 3 weeks after the birth of the juveniles, according to Zoufal 2005) are shown. Further, the development of beech seeds in the study area and the duration of the supplemental feeding experiment are plotted 
which we found juveniles only (capture weeks 39 and 41). Body masses and testes volumes were not normally distributed (Shapiro-Wilk test) and therefore these variables were log-transformed. Repeated measurements of the animals were analyzed using linear mixed effect models, entering differences between individual intercepts as the random effect. To analyze variation in body mass during and after the supplemental feeding experiment, we tested for effects of age, sex, supplemental feeding and capture week.

Reproductive activity of females was analyzed using general linear models, with having reproduced or not as the binominal response variable. We tested for effects of supplemental feeding, age-class, and body mass during the supplemental feeding period (i.e., prior to first birth of young) on subsequent reproduction. Litter size was analyzed with linear models, and we tested for effects of ageclass and supplemental feeding. Due to insufficient data we could not test for the influence of body mass during the feeding experiment on litter size later in the year.

To analyze variation in testes size we tested for effects of age, supplemental feeding and capture week. Factors affecting the tangibility of testes were investigated with generalized mixed effect models (with the presence or absence of tangible testes as the binominal response variable), again entering the individual as the random effect, and testing for effects of age, supplemental feeding and capture week. The time courses of testes volume and of the probability of tangible testes were best described by quadratic polynomes of the variable "capture week." In contrast to females we could not test for the influence of the body mass on the reproductive decision of males. While in females the main reproductive costs arise during lactation, in males reproductive activity results in a body mass decrease already at the very beginning of the active season (Bieber 1998; Fietz et al. 2004; this study). Therefore, body mass could not be used as an independent predictor of male reproductive decisions in our statistical analysis.

Starting from fully parameterized models, terms were eliminated in a stepwise procedure. Model selection followed the parsimony principle using the Akaike Information Criterion, which incorporates both, the complexity of an estimated model and how well the model fits the data (Akaike 1973). We used Likelihood-ratio tests to compare models. If models did not significantly differ, the model with fewer terms was selected. If not stated otherwise we give mean \pm standard errors. All statistical analyses were carried out with the statistical package $\mathrm{R}$ version 2.6.1 (R Development Core Team 2007).

\section{Results}

During the whole active season we captured 421 sexually mature dormice (i.e., yearlings and adults), 286 in the control area and 135 in the supplemental feeding area (Table 1). In 2007 recapture rates of individual dormice were low. Most individuals $(65.6 \%)$ were only caught once (range $=1-7$ ). The population structure in these areas differed neither in sex-ratios $\left(\chi^{2}=0.496, d f=1, P=0.481, N=421\right)$ nor in agestructure $\left(\chi^{2}=0.907, d f=1, P=0.341, N=421\right)$.

Body mass during the supplemental feeding experiment

In females, supplemental feeding had no effect on their body mass (Fig. 2a). Their body mass during the supplemental feeding period (until week 30 ) was best predicted by their age alone (Table 2), which explained most of the variation in body mass $\left(R^{2}=0.97\right)$. During this time adult females had a body mass of $101.4 \pm 2.3 \mathrm{~g}(N=33)$, while yearling females weighted only $69.8 \pm 1.7 \mathrm{~g}(N=28$; data pooled for both areas).

Unlike in females, body mass of males was influenced by the supplemental feeding (Table 2). Males in the supplemental feeding area $(N=129)$ were $5.3 \pm 2.5 \mathrm{~g}$ heavier than those in the control area $(N=55)$. During the supplemental feeding experiment adult males had a higher body mass $(104.5 \pm 1.6 \mathrm{~g}, \quad N=91)$ than yearling males $(72.3 \pm 0.9 \mathrm{~g}, N=93)$ and rapidly lost weight during the first weeks of the active season (Fig. 2b). The best model $\left(R^{2}=0.96\right)$ to describe the variation of body mass in males included capture week, the supplemental feeding and age. There was also a significant interaction between capture week and age, caused by different time courses of body mass in adult and yearling males. Whereas adult males constantly lost weight during weeks 23-29, body mass remained almost constant in yearling males (Fig. 2b).

Body mass after the supplemental feeding experiment

Both sex, age and treatment groups gained much weight in the weeks after the supplemental feeding had stopped (Fig. 2). In females only the capture week and age had an effect on their body mass. Prior supplemental feeding did not influence their body mass during this time, but there is a tendency that females in the control area gained a little

Table 1 Number of captured individuals according to sex, age and treatment during the whole active season

\begin{tabular}{lccc}
\hline & Yearling & Adult & Total \\
\hline Female & & 39 & 131 \\
Control & 53 & 24 & \\
$\quad$ Supplemental feeding & 15 & & \\
Male & & 89 & 290 \\
$\quad$ Control & 105 & 43 & \\
Supplemental feeding & 53 & 195 & 421 \\
Total & 226 & & \\
\hline
\end{tabular}




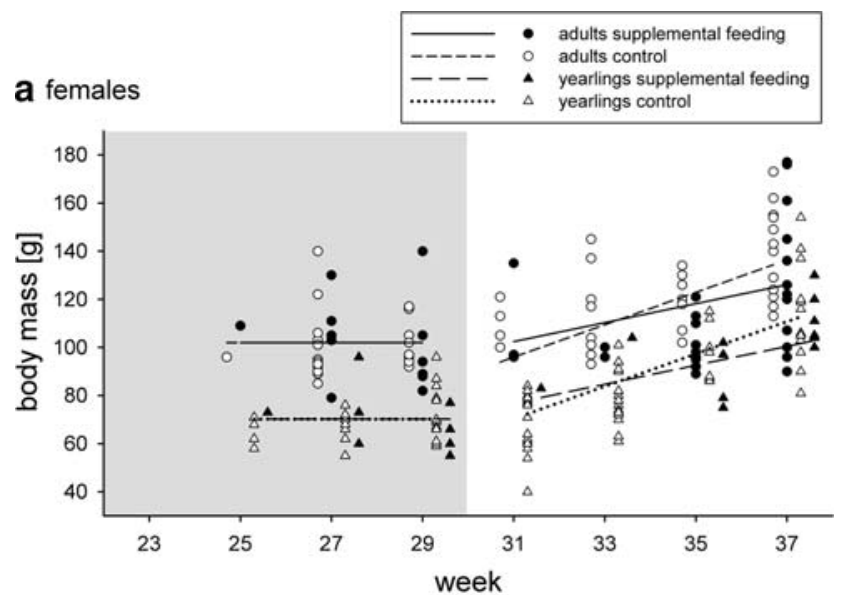

b males

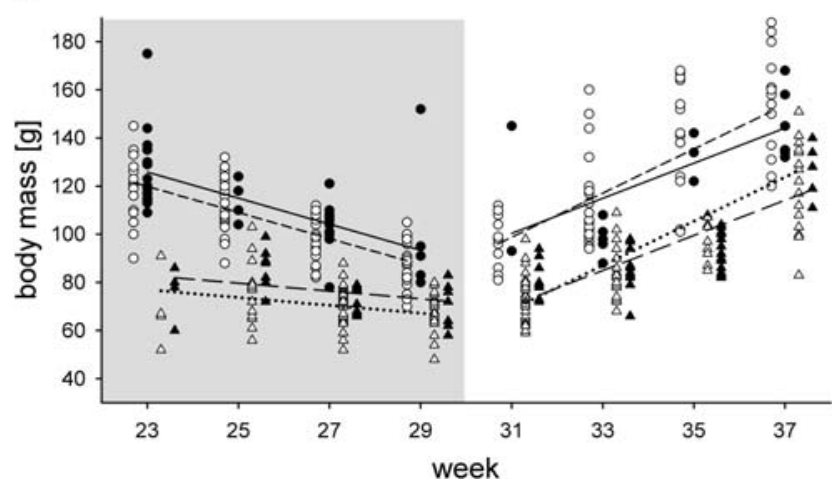

Fig. 2 Body masses of adult and yearling dormice during (gray area) and after the supplemental feeding. Regression lines are drawn according to the estimates of the best model (see Table 2). Note that although individual dormice may be represented more that once, the regression lines are corrected for the individuals

more weight per week than in the supplemental feeding area (Table 2).

In males not only the capture week and their age had a significant effect, their body mass was also influenced by the supplemental feeding (Table 2). Males in the supplemental feeding area were lighter and gained less body mass per week than those in the control area (Fig. 2b).

Reproduction in females

The proportion of reproductively active females was significantly increased in the supplemental feeding area (Fig. 3; Table 3). As our statistical analyses also included age-class, this effect of supplemental feeding was independent from differences in age-class proportions between the areas. Whereas in the control area only 21 out of 36 (58.3\%) of the females reproduced, we found 22 out of 23 (95.7\%) females in the supplemental feeding area to be reproductively active. Importantly, body mass did not affect the reproductive decision (Fig. 4; full model: $\chi^{2}=1.209$, $d f=1, P=0.272 ; N=19)$, and was therefore excluded
Table 2 ANOVA-tables (final models) of the factors affecting body mass in female and male mature dormice during and after the supplemental feeding experiment

\begin{tabular}{llrc}
\hline & $d f$ & \multicolumn{1}{l}{$F$} & \multicolumn{1}{l}{$P$} \\
\hline During the supplemental feeding & & & \\
Females $(N=61)$ & & & \\
Age & 1,59 & 117.194 & $<0.001$ \\
Males $(N=184)$ & & & \\
Week & 1,55 & 253.177 & $<0.001$ \\
Supplemental feeding & 1,181 & 17.398 & $<0.001$ \\
Age & 1,181 & 359.938 & $<0.001$ \\
Week $\times$ age & 1,55 & 21.700 & $<0.001$ \\
After the supplemental feeding & & & \\
Females $(N=94)$ & & & \\
Week & 1,37 & 114.931 & $<0.001$ \\
Supplemental feeding & 1,91 & 0.115 & 0.7355 \\
Age & 1,91 & 52.800 & $<0.001$ \\
Week $\times$ supplemental feeding & 1,37 & 3.729 & 0.0612 \\
Males $(N=156)$ & & & \\
Week & 1,47 & 880.405 & $<0.001$ \\
Supplemental feeding & 1,153 & 4.043 & 0.046 \\
Age & 1,153 & 158.823 & $<0.001$ \\
Week $\times$ supplemental feeding & 1,47 & 9.394 & 0.004 \\
\hline & & &
\end{tabular}

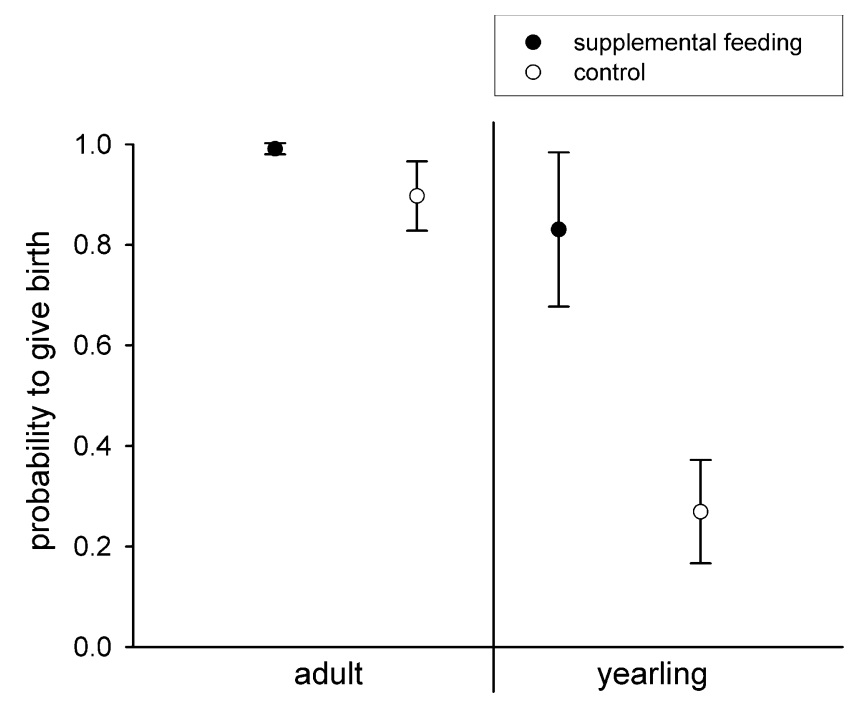

Fig. 3 Predictions for the probability to give birth (mean \pm SEM) depending on age and supplementary feeding area, calculated from the final model describing the factors determining reproduction in females (see Table 3). $N=18 / 18 / 5 / 18$

from the final model (Table 3 ). In both areas more adult $(94.4 \%, N=36)$ than yearling females $(39.1 \%, N=23)$ reproduced. Although it seems that supplemental feeding increased the proportion in yearlings at a higher rate than in adult females (Fig. 3), the interaction term between age and supplemental feeding was not significant (full model: 
Table 3 ANOVA table (final models) of the factors affecting reproduction in adult females and reproductive competence in adult males

\begin{tabular}{llrrr}
\hline & $d f$ & $\chi^{2}$ & \multicolumn{1}{l}{$P$} \\
\hline Females & & & & \\
Reproductive decision $(N=59)$ & & & \\
Supplemental feeding & 1 & 7.045 & 0.008 & \\
Age & 1 & 17.936 & $<0.001$ & \\
Litter size $(N=24)$ & & & & \\
Supplemental feeding & 1,21 & & 0.013 & 7.433 \\
Age & 1,21 & & 0.030 & 5.431 \\
Males & & & & \\
Tangibility of testes $(N=290)$ & & & & \\
Time & 2 & 160.59 & $<0.001$ & \\
Supplemental feeding & 1 & 10.871 & $<0.001$ & \\
Testes size $(N=234)$ & & & & \\
Time & 2,92 & & $<0.001$ & 171.924 \\
Supplemental feeding & 1,92 & & $<0.001$ & 30.635 \\
Age & 1,230 & & $<0.001$ & 119.348 \\
Time $\times$ supplemental feeding & 2,92 & & $<0.001$ & 15.350 \\
Time $\times$ age & 2,92 & & 0.001 & 7.487 \\
Supplemental feeding $\times$ age & 1,230 & & 0.014 & 6.171 \\
\hline
\end{tabular}

The term "time" represents fits to a quadratic polynomial of capture week

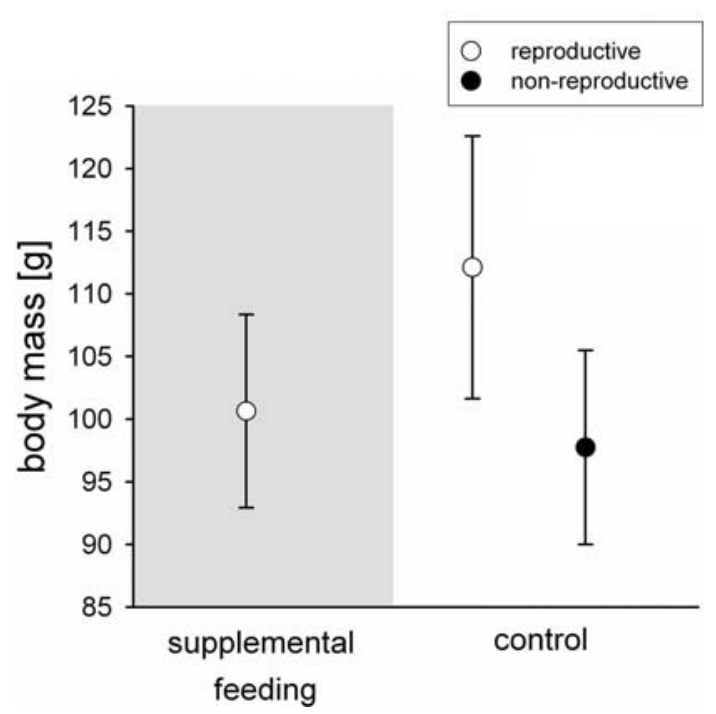

Fig. 4 Body masses of adult female dormice (mean \pm SEM) during the supplemental feeding experiment. Since their body mass did not change during this time we took the mean body mass of those we captured more than once. Neither reproduction $(F=0.700, d f=1, P=0.422, N=13)$ nor the supplemental feeding $(F=0.853, d f=1, P=0.377, N=13)$ influenced their body mass. $N=7 / 2 / 4$. Note that there were no nonreproductive adult females in the supplemental feeding area

$\left.\chi^{2}=0.360, d f=1, P=0.548, N=59\right)$. The final model with supplementary feeding and age as the predictive variables was able to predict the reproductive decision in $86.4 \%$ of all cases correctly.
Yearlings had smaller litters than adult females (yearlings: $4.3 \pm 0.3, N=4$; adults: $5.6 \pm 0.4, N=20$ ). Females in the supplemental feeding area showed a significantly lower litter size $(4.8 \pm 0.5, N=13)$ compared to females at the control area $(6.1 \pm 0.5, N=11)$ (Table 2). Among adult females we found a litter size of $6.8 \pm 0.4(N=8)$ in the control area, while females in the supplemental feeding area had only $4.8 \pm 0.5(N=12)$ juveniles. Yearling females at the control area had a litter size of $4.3 \pm 0.3$ $(N=3)$, but we could only obtain the litter size from one yearling female at the supplemental feeding area, which had four juveniles.

\section{Reproductive state in males}

In the supplemental feeding area $11.4 \pm 3.5 \%(N=290)$ more males than in the control area had tangible testes (Table 3). Expectedly, the proportion of males with tangible testes changed over the active season: During the mating season (week 25-28) a high proportion $(96 \%, N=122)$ of males had tangible testes whereas towards the end of the active season (weeks 35-37) most males (76\%, $N=84$ ) had regressed testes. The age of the males had no effect on the tangibility of their testes and this term was therefore removed from the final model ("age" term in the full model: $\left.\chi^{2}=0.433, P=0.511 ; N=290\right)$.

Among those males with tangible testes, adult males had significantly larger testes (adult $N=105$, yearling $N=129$; Table 3). This effect was most distinct during the mating season (week 25-28), when adult males had a testes size of $648.0 \pm 19.2 \mathrm{~mm}^{3}(N=58)$ and yearlings a testes size of $343.2 \pm 15.5 \mathrm{~mm}^{3}(N=59$; Table 3). Supplemental feeding did not increase the maximum testes size in adults, their mean testes volume during the main mating season (week 25) was $706.4 \pm 30.4 \mathrm{~mm}^{3}(N=26)$ in the control area, and $672.6 \pm 61.5 \mathrm{~mm}^{3}(N=7)$ in the supplemental feeding area. However, males at the supplemental feeding area maintained increased testes sizes for 4 weeks (27-31) longer than those in the control area (Fig. 5). This was reflected by a significant time $\times$ supplemental feeding interaction (Table 3 ).

In contrast to adult males, supplementary feeding induced a significant increase in testes size among yearlings. During the main mating season mean testes size of yearlings was $287.8 \pm 31.27 \mathrm{~mm}^{3}(N=14)$ in the control area and $428.3 \pm 55.5 \mathrm{~mm}^{3}(N=9)$ in the supplemental feeding area (hence the significant supplemental feeding $\times$ age interaction, Table 3 ).

\section{Discussion}

Increases in body mass and reproduction due to the provision of high energetic food is a common result in supplemental 


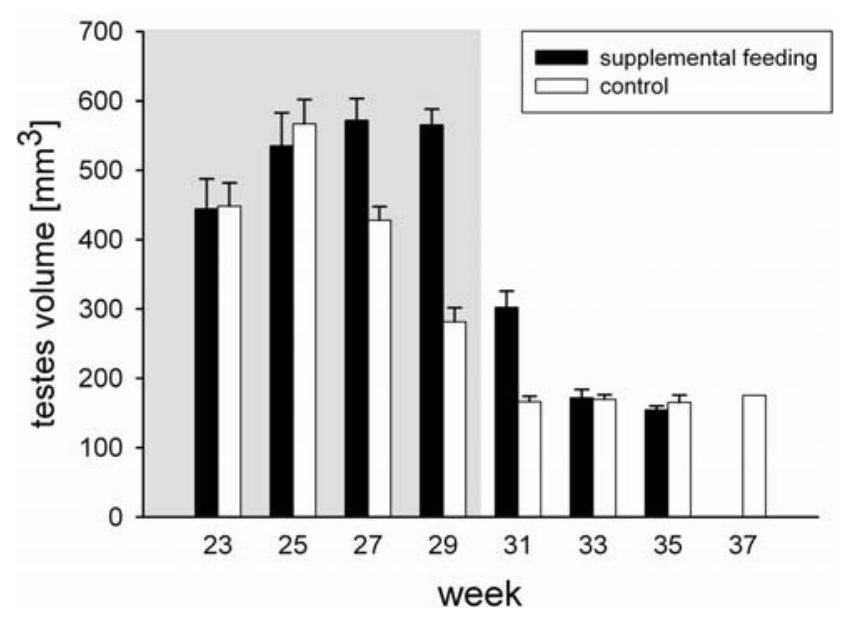

Fig. 5 Testes volume (mean + SEM) of adult and yearling males (pooled). The gray area marks the time period in which supplemental food was provided. Supplemental feeding $N=13 / 16 / 22 / 13 / 9 / 17 / 11 / 0$; control $N=15 / 40 / 59 / 40 / 37 / 31 / 8 / 1$

feeding experiments and has been found in many rodents (Cole and Batzli 1978; Eifler et al. 2003; Neuhaus 2000; Watts 1970). In those studies, supplemental feeding resulted in higher body masses, which enabled animals to allocate more energy reserves to reproduction. Our present results indicate that increased reproduction in female dormice was not the result of a higher body mass. Although the proportion of reproducing females was significantly higher in the supplemental feeding area, the surplus food had no effect on their body mass. Note that in dormice, effects of gestation can be neglected in this context, because in this species pregnancy does not lead to noticeable weight gains (Bieber 1998) If they did not use the energy from the seeds to store it for the energetically challenging period of lactation later in the season [peak lactation takes place about 3 weeks after parturition (Zoufal 2005)], the question remains what happened to the additional calories? Since we found a high amount of empty hulls and because sunflower seeds significantly affected reproduction, it seems clear that the dormice fed on them. If they needed a high amount of energy, e.g., to invest in gonadal growth, we would expect that reproductive females loose body mass compared to non-reproductive females - which was not the case. A likely explanation is that due to the easily accessible food resource females in the supplemental feeding area reduced their time normally spent on foraging behavior and thereby lessened their predation risk. In this way they would not have obtained additional energy, which explains why we found no difference in body mass between females in the supplemental feeding and control area during the mating season. Clearly, those dormice which do not invest in reproduction can start to gain body fat reserves for hibernation earlier. This could explain why dormice within the control area, in which the proportion of non-reproductive animals was higher, increased their body mass after the mating period faster than those in the supplemental feeding area.

The finding that body mass per se (as an indicator for body condition) is not the determining factor for reproductive decisions in dormice, was not unexpected however. Previous studies have shown that dormice had even higher body masses in years without reproduction, although energy rich seeds were not available (Pilastro et al. 2003; Ruf et al. 2006). Note that this weight difference is not simply a consequence of allocation of energy into reproduction as it is found even in spring, prior to the reproductive season (Bieber 1998; Pilastro et al. 2003; Ruf et al. 2006). Also, mature dormice do not require high caloric seeds for pre-hibernation fattening, but can sufficiently gain weight feeding on foliage, fruits and miscellaneous other food sources alone (Fietz et al. 2005). Thus, the strong effect of supplemental feeding on reproductive decisions in our present experiment indicates that dormice seem to primarily respond to the "information content" of energy rich seeds rather than utilizing them to build up fat stores as a prerequisite for reproduction. In other words, high seed availability in spring and early summer (i.e., the abundance of early stages of beechnuts or acorn under natural conditions) primarily seems to act as an environmental signal for the upcoming food availability in late summer/fall. The adaptive significance of exploiting this signal is evident, because in dormice, this time is the crucial, highly energy-demanding period for lactating females and fast-growing juveniles (Bieber and Ruf 2004; Zoufal 2005; Kager and Fietz 2009).

Surprisingly, females in the supplemental feeding area had smaller litter sizes than those in the unaltered area. Since we determined litter sizes not before the juveniles were about 10 days old, it is possible that those litter sizes do not represent the actual number of juveniles at birth. Because we terminated supplemental feeding around the time when young were born females experienced a sudden drop in food resources. Conceivably, some females may have decreased litter size after birth to adjust to this suddenly lower food availability (Weber and Olsson 2008). For those females which were only "lured" into reproducing by the supplemental food (and would not have reproduced without it), re-adjusting reproductive effort may well maximize their life-time reproductive success. This explanation is supported by a study of Kager and Fietz (2009), who found significantly larger litter sizes in supplementary fed free-ranging dormice, when food was provided over the entire active season. Sudden changes in food availability can also occur under natural conditions. Although the availability of seed buds represents a good predictor for the future mast situation, beech may drop seeds before maturity due to a drought in summer (Piovesan and Adams 2005). 
In males, supplemental feeding caused a higher fraction of dormice (of both age classes) with tangible testes, a significant prolongation of the time period with fully developed testes, and increased testes sizes among yearlings (which had probably reached a maximum among adults). Previous studies have already shown that large fractions of males may stay in a state of gonadal regression in years when seeds are absent, despite emerging from hibernation in a good body condition (Bieber 1998; Pilastro et al. 2003). This fact supports the view that large body energy reserves are not a prerequisite for testes growth in dormice. Therefore, it seems that, as in females, the availability of seeds in spring primarily provided an environmental signal, rather than a necessary source of energy, that triggered testes growth in males.

However, in contrast to females, males apparently allocated energy to reproductive activity already in spring and early summer, and males on the supplemental feeding area likely made use of the additional resources. The early investment of energy was indicated by the rapid weight loss among adults prior to and during the mating season (Fig. 2b). Those energetic costs arise mainly due to intrasexual competition, increased locomotor activity and reduced heterothermic capacity in sexually active males (Bieber 1998; Fietz et al. 2004). Yearling males, which showed no decrease in their body masses, probably do not invest in intramale competition (due to their low body mass they would most likely be inferior to adult males), and may have limited opportunities to actually reproduce. Their chances to fertilize females will be enhanced however by increased testes sizes, which are correlated with sperm numbers (Joy et al. 1980; Parker 1990). Also, it seems evident that males, given access to a high caloric diet, will benefit from a prolonged period of reproductive capability. Since juveniles born early in the season reach higher prehibernation body masses and have better chances to survive winter it is beneficial for males to become sexually active as soon as possible (Pilastro et al. 1994). As long as there are receptive females present, it might also pay off to lengthen the period during which large testes are maintained. From our last calculated birth date (on August 28th) we assessed that mating had been at week 30 . At this point of time it is most likely that all males in the control area had already smaller testes, while at least some males in the supplemental feeding area had still fully developed testes. The detriment of this prolonged sexual activity was a lesser gaining of body mass toward the end of the active season which might influence their hibernation survival.

Yearling dormice are not fully grown after their first hibernation, but a number of them reproduced nonetheless. In fact, the effect of supplemental feeding was most pronounced among yearling females (Fig. 3.), although this difference in the responses between adults and yearlings was not statistically significant. Even when provided with seeds, yearlings were apparently not able to spend as much energy as adults for reproduction (e.g., yearlings had lower litter sizes), because they had to invest in growth as well (Pianka and Parker 1975). A lower investment into reproduction among yearlings can also be found in other hibernators. However, in most species studied up to date, body mass seems to be a crucial factor for the onset of reproductive activity (e.g., Broussard et al. 2003; Dobson and Michener 1995; Millesi et al. 1999; Neuhaus et al. 2004). It is surprising then that for female yearling dormice in our study, body mass was still neither a decisive nor even a statistically significant factor affecting their reproductive decisions. The fact that most supplementary fed yearlings reproduced despite their inferior initial conditions supports our conclusion that they used high energetic seeds as an environmental cue, independent from their body mass.

These results raise the question which components of beech (or similar) seeds could provide the "environmental cue" which triggers, or, alternatively, may directly limit reproduction in dormice if they are absent from the diet. Our study indicates that the actual seed type, i.e., sunflower seeds versus beechnuts, is not the determining factor. Thus, it seems unlikely that reproduction is affected by specific secondary plant components present in the seeds of these relatively unrelated plant species. White (2007) suggested that the availability of amino-acids in inflorescences and unripe seeds could enhance reproduction in mammals which seem to "predict" future food availability. At least for dormice, however, amino-acid availability is an implausible crucial factor, because the dry weight proportion of amino-acids does not differ between beechnuts and beech leaves, which are always abundant and provide an important food resource for dormice (Deutsche LandwirtschaftsGesellschaft 1982). Also, dormice can feed on other items which are rich on amino-acids as well (Nowakowski et al. 2006; USDA 2007).

Another possibly limiting dietary component for reproduction in mammals and birds are certain minerals or vitamins (Allen and Ullrey 2004; Speakman 2008). Particularly lack of calcium, zinc, copper, vitamin $\mathrm{A}$ and $\mathrm{B}_{12}$ has been shown to impair reproduction in mammals, but they are either abundant in other food resources (e.g., beech leaves) or are have a low content in both beech and sunflower seeds (Barclay 1994; Bauer et al. 1997; Mankovská 1998; USDA 2007). A dietary component that occurs at very high concentrations in seeds are polyunsaturated fatty acids (PUFAs, particularly, Omega 6-PUFAs). However, since the PUFA content in white adipose tissue in spring does not differ between reproducing and non-reproducing dormice, PUFAs apparently are not a limiting resource for reproduction either (Fietz et al. 2005). Thus, it seems that the most parsimonious explanation for the observed effects of seeds 
on reproduction in dormice is indeed their high energy content, which, however, represents a decisive environmental signal, rather than a directly limiting factor. The fact that dormice respond not only to the availability of beechnuts and acorn, but also to sunflower seeds, that are not part of their natural diet, suggests that a lack of differentiation between high-caloric diets may be adaptive. Dormice can also inhabit areas in which other seeds, such as hazelnuts or chestnuts are the dominating food (Sara and Casamento 1995). Using the energy content of food as an environmental signal that regulates reproductive decisions would allow dormice to breed more continually in habitats in which food resources fluctuate less than beechnuts and acorn. Of course, the actual physiological pathways by which high energy (particularly fat) intake early in the season affects the propensity for reproduction in this species remain to be clarified.

Coincidently, Fietz et al. (2009) and Kager and Fietz (2009) simultaneously conducted a similar supplementary feeding study on dormice. At first glance, the results from that study seem to contradict our present observations, because they found no increase in reproductively active dormice when they supplementary fed them with sunflower seeds and rodent chow provided in feeders above the nestboxes. However, there are several possible explanations for this apparent discrepancy. First, in the experiment by Fietz et al. (2009) sunflower seeds were predated at a very high rate (perhaps entirely) by birds, and the remaining rodentchow had a $\sim 44 \%$ lower energy content than the consumed parts of sunflower seeds (Fietz et al. 2009). Although the energy provided in that study enabled them to gain some body mass, the additional energy still may not have been sufficient to increase the proportion of reproductively active animals. This suggests that diet may provide a reproductive cue only if it's energy content exceeds a certain threshold. Second, while we found the strongest increase among supplementary fed yearlings, Fietz et al. (2009) and Kager and Fietz (2009) investigated the effect of supplementary feeding on adult individuals only. Further, the impact of supplemental food is most likely dependent on the availability of natural food resources. In a high mast seeding year, where energy-rich food is abundant and most animals would reproduce anyway, supplemental feeding would clearly have no effect on the proportion of reproductively active individuals (Kager and Fietz 2009).

However, the results of our present study suggest that dormice, at least in years with intermediate natural food supply, can use the occurrence of an energy rich food, like seed buds of beech, early in the active season to adjust reproductive decisions. Further research will have to show whether or not this is indeed a universal mechanism that allows dormice of all age-classes, and under all conditions of tree-seeding, to predict the autumnal mast situation and to regulate reproductive investments in pulsed-resource habitats.

Acknowledgments We thank R. Litschauer (Federal Forest Office) for information and data on beech mast and the Austrian Forestral Agency for the admission to use the study site and for provision with forest inventory data. Special thanks to F. Schieferdecker for the building of nearly 200 nest-boxes to support the local avian fauna and for his permission to use them in our dormouse-study. This project was supported by the city of Vienna, the province of Lower Austria and the Austrian Science Fund (FWF, Project P20534-B17). We declare that the experiments were approved by the University of Veterinary Medicine of Vienna ethics committee and comply with the current laws of Austria, where the experiment was performed.

Open Access This article is distributed under the terms of the Creative Commons Attribution Noncommercial License which permits any noncommercial use, distribution, and reproduction in any medium, provided the original author(s) and source are credited.

\section{References}

Adamík P, Král M (2008) Climate- and resource-driven long-term changes in dormice populations negatively affect hole-nesting songbirds. J Zool 275:209-215

Akaike H (1973) Information theory and extension of the maximum likelihood principle. In: Petrov BN, Csaki F (eds) Proceedings of second international symposium on information theory. Akademia Kaido, Budapest, pp 267-281

Allen ME, Ullrey DE (2004) Relationships among nutrition and reproduction and relevance for wild animals. Zoo Biol 23:475-487

Barclay RMR (1994) Constraints on reproduction by flying vertebrates: energy and calcium. Am Nat 144:1021-1031

Bauer G, Schulze ED, Mund M (1997) Nutrient contents and concentrations in relation to growth of Picea abies and Fagus sylvatica along a European transect. Tree Physiol 17:777-786

Bieber C (1998) Population dynamics, sexual activity, and reproduction failure in the fat dormouse (Myoxus glis). J Zool 244:223-229

Bieber C, Ruf T (2004) Seasonal timing of reproduction and hibernation in the edible dormouse (Glis glis). In: Barnes BM, Carey HV (eds) Life in the cold: evolution, mechanisms, adaptation, and application Twelfth international hibernation symposium, biological papers of the University of Alaska, number 27. Fairbanks, Alaska, pp 113-125

Boutin S, Wauters LA, McAdam AG, Humphries MM, Tosi G, Dhondt AA (2006) Anticipatory reproduction and population growth in seed predators. Science 314:1928-1930

Bronson FH (1988) Seasonal regulation of reproduction in mammals In: Knobil E, Neill J (eds) The physiology of reproduction. Raven Press Ltd, New York, pp 1831-1872

Broussard DR, Risch TS, Dobson FS, Murie JO (2003) Senescence and age-related reproduction of female Columbian ground squirrels. J Anim Ecol 72:212-219

Butterstein GM, Schadler MH (1988) The plant metabolite 6-methoxybenzoxazolinone interacts with follicle-stimulating hormone to enhance ovarian growth. Biol Reprod 39:465-471

Cole FR, Batzli GO (1978) Influence of supplemental feeding on a vole population. J Mammal 59:809-819

Development Core Team R (2007) R: a language and environment for statistical computing (2.6.1). R Foundation for Statistical Computing, Vienna

Dobson FS, Michener GR (1995) Maternal traits and reproduction in Richardson's ground squirrels. Ecology 76:851-862 
Eifler MA, Slade NA, Doonan TJ (2003) The effect of supplemental food on the growth rates of neonatal, young, and adult cotton rats (Sigmodon hispidus) in northeastern Kansas, USA. Acta Oecol 24:187-193

Fietz J, Dausmann KH, Heldmaier G, Schlund W, Regelmann M (2004) Energetic constraints on sexual activity in the male edible dormouse (Glis glis). Oecologia 138:202-209

Fietz J, Pflug M, Schlund W, Tataruch F (2005) Influences of the feeding ecology on body mass and possible implications for reproduction in the edible dormouse (Glis glis). J Comp Physiol B 175:45-55

Fietz J, Kager T, Schauer S (2009) Is energy supply the trigger for reproductive activity in male edible dormice (Glis glis)? J Comp Physiol B 179:829-837

Goldman BD (1999) The circadian timing system and reproduction in mammals. Steroids 64:679-685

Hilton GM, Packham JR (2003) Variation in the masting of common beech (Fagus sylvatica L) in northern Europe over two centuries (1800-2001). Forestry 76:319-328

Joy JE, Melnyk RB, Mrosovsky N (1980) Reproductive cycles in the male dormouse (Glis glis). Comp Biochem Physiol A Physiol 67:219-221

Kager T, Fietz J (2009) Food availability in spring influences reproductive output in the seed-preying edible dormouse (Glis glis). Can J Zool 87:555-565

König L (1960) Das Aktionssystem des Siebenschläfers (Glis glis L). Z Tierpsychol 17:427-505

König WD, Knops JMH (2000) Patterns of annual seed production by Northern Hemisphere trees: A global perspective. Am Nat 155:59-69

Landwirtschafts-Gesellschaft Deutsche (1982) DLG Futterwerttabellen für Wiederkäuer, 4 edn. DLG-Verlag, Frankfurt am Main

Malaivijitnond S, Kiatthaipipat P, Cherdshewasart W, Watanabe G, Taya K (2004) Different effects of Pueraria mirifica, a herb containing phytoestrogens, on LH and FSH secretion in gonadectomized female and male rats. J Pharmacol Sci 96:428-435

Mankovská B (1998) The chemical composition of spruce and beech foliage as an environmental indicator in Slovakia. Chemosphere 36:949-953

Millesi E, Huber S, Everts LG, Dittami JP (1999) Reproductive decisions in female European ground squirrels: factors affecting reproductive output and maternal investment. Ethology 105:163-175

Neuhaus P (2000) Weight comparisons and litter size manipulation in Columbian ground squirrels (Spermophilus columbianus) show evidence of costs of reproduction. Behav Ecol Sociobiol 48:75-83

Neuhaus P, Broussard DR, Dobson FS, Murie JO (2004) Age of primiparity and implications of early reproduction on life history in female Columbian ground squirrels. J Anim Ecol 73:36-43
Nowakowski WK, Remisiewicz M, Kosowska J (2006) Food preferences of Glis glis (L), Dryomys nitedula (pallas) and Graphiurus murinus (smuts) kept in captivity. Pol J Ecol 54:369-378

Ostfeld RS, Keesing F (2000) Pulsed resources and community dynamics of consumers in terrestrial ecosystems. Trends Ecol Evol 15:232-237

Parker GA (1990) Sperm competition games: raffles and roles. Proc R Soc B Biol Sci 242:120-126

Pianka ER, Parker WS (1975) Age-specific reproductive tactics. Am Nat 109:435-464

Pilastro A, Gomiero T, Marin G (1994) Factors affecting body mass of young fat dormice (Glis glis) at weaning and by hibernation. J Zool 234:13-23

Pilastro A, Marin G, Tavecchia G (2003) Long living and reproduction skipping in the fat dormouse. Ecology 84:1784-1792

Piovesan G, Adams JM (2005) The evolutionary ecology of masting: does the environmental prediction hypothesis also have a role in mesic temperate forests? Ecol Res 20:739-743

Ruf T, Fietz J, Schlund W, Bieber C (2006) High survival in poor years: life history tactics adapted to mast seeding in the edible dormouse. Ecology 87:372-381

Sara M, Casamento G (1995) Distribution and ecology of dormice (Myoxtdae) in Sicily: a preliminary account. Hystrix 6:161-168

Schlund W (1997) Die Tibialänge als Maß für Körpergröße und als Hilfsmittel zur Altersbestimmung bei Siebenschläfern (Myoxus glis L). Mamm Biol 62:187-190

Schlund W, Scharfe F, Ganzhorn JU (2002) Long-term comparison of food availability and reproduction in the edibte dormouse (Glis glis). Mamm Biol 67:219-232

Speakman JR (2008) The physiological costs of reproduction in small mammals. Philos Trans R Soc B Biol Sci 363:375-398

USDA (2007) USDA national nutrient database for standard reference, Release 21 Nutrient Data Laboratory Home Page. http://wwwarsusdagov/nutrientdata

Vietinghoff-Riesch A (1960) Der Siebenschläfer (Glis glis L). Monogr Wildsäugetiere 14:109-136

Watts CHS (1970) Effect of supplementary food on breeding in woodland rodents. J Mammal 51:169-171

Weber EM, Olsson IAS (2008) Maternal behaviour in Mus musculus sp: an ethological review. Appl Anim Behav Sci 114:1-22

White TCR (2007) Mast seeding and mammal breeding: can a bonanza food supply be anticipated? N Z J Zool 34:179-183

Yang LH, Bastow JL, Spence KO, Wright AN (2008) What can we learn from resource pulses? Ecology 89:621-634

Zoufal K (2005) Energiehaushalt des Siebenschläfers (Glis glis) während der Jungenaufzucht. Diploma thesis, University of Vienna, Austria 